BLOOM, Harold. Cabala e crítica. Trad. Monique Balbuena. Rio de Janeiro: Biblioteca Pierre Menard / IMAGO, 1991.

\title{
A Cabala como teoria da linguagem: transferência e desvio
}

\section{Vívien Gonzaga e Silva*}

Tratar de uma tradição esotérica como operador teórico não é um empreendimento que se possa abraçar facilmente, mesmo porque há um conjunto de valores que demarcam a cultura ocidental no sentido de distanciar o conhecimento produzido no campo estrito da ciência, particularmente na perspectiva da modernidade, de outros saberes que não se mostram propensos a uma investigação objetiva. É essa, no entanto, a proposta de Cabala e crítica, de Harold Bloom, que busca, pela leitura dos tratados cabalísticos, reconhecer uma "tradição da tradição", na qual estão imbricadas as noções de dar e receber, como processos análogos de "transferência" (p. 67). Por isso, é necessário cuidado ao se buscar, na etimologia, algum entendimento inicial do propósito de Bloom, já que o termo "cabala" teria, então, um sentido mais restrito, a partir da raiz semítica "qbl" (receber), contemplando apenas um dos aspectos de um fenômeno que, na verdade, dá-se em dupla direção. De modo cuidadoso, portanto, o ensaio de Bloom põe em foco as "relações de transferência e desvio ocorrendo entre os textos de precursores e poetas tardios", importando, dentro do projeto do autor, "a medida de distanciamento, de liberação de um texto com respeito a seu antecessor" (p. 15).

No primeiro capítulo, Bloom procura rastrear os movimentos teosóficos que, de algum modo, contribuíram para a formação de um corpus textual que passou a ser associado à Cabala judaica. Como não poderia ser de outra forma, reconhece - sem angústia - a valia dos estudos de Gershom Scholem, que apontam para as origens da Cabala no início da era cristã. Porém, Bloom irá considerar as principais concepções filosófico-religiosas que proliferaram nos primeiros séculos cristãos, no mundo mediterrâneo oriental, como um substrato, ainda difuso, advindo do esoterismo judaico, indispensáveis para a compreensão da Cabala, mas não como sua origem histórica. É a partir do surgimento do Séfer Yetziráh (Livro da Criação), em torno do século III, que essa origem será demarcada pelo estudioso. Para o crítico, a importância desse pequeno texto, atribuído ao Rabi Akiba, está na introdução da "noção estrutural central" da Cabala, as Sefirót, os dez números primordiais que, numa perspectiva neopitagórica, estariam invocados no trabalho divino da Criação. $\mathrm{O}$ segundo tratado relevante para a constituição da Cabala viria cerca de mil anos depois: o Séfer ha-Bahir (ou Livro luminoso). Nesse livro, cujo aspecto fragmentário é ressaltado por Bloom, estaria um desenvolvimento considerável da noção das Sefirót, já entendidas como "emanações divinas através das quais toda a realidade é estruturada" (p. 32). Essas emanações se apresentam, de acordo com o autor, como atributos de Deus, "princípios e poderes divinos, e também luzes celestes, que participam da obra da Criação" (p. 33), sendo também no Séfer ha-Bahir que se inaugura o "estilo" cabalístico, como construção literária, especialmente através do uso de parábolas.

O Séfer ha-Zohar (Livro do esplendor) virá completar a tríade privilegiada por Bloom em sua abordagem inicial. A coletânea de manuscritos, cuja escrita é atribuída Moisés de Leon, entre 1280 e 1286, veio a constituir o que Bloom, em seu modo peculiar de expressão, chamou de "o único livro notável de todo o esoterismo ocidental". Seja como for, é importante considerar que o surgimento do Zohar permite à Cabala transformar-se num "sistema completo de especulação". (p. 33). O que se apreende daí é o que de fato importa numa abordagem da Cabala como um conjunto de comentários e interpretações dos textos sagrados e, conseqüentemente, como uma "teoria da influência" (p. 38). A complexidade do processo constitutivo desse sistema - na verdade, um apanhado de textos dispersos ao longo de séculos, surpreendentemente preservados pela tradição oral, e estabelecidos (se é que se pode dizer assim) pela combinação de línguas e linguagens - é similar ao processo que se pode entrever na formação de um poeta a partir de outro, como propõe o estudo. Boa parte desse seu primeiro capítulo 
será dedicada à exposição dos conceitos e imagens fundamentais da Cabala clássica, cuja principal sustentação encontra-se na doutrina das Sefirót, ainda apegada ao gnosticismo e, principalmente, ao neoplatonismo de Plotino (c. 205-270). Mas, é ao tratar da Cabala moderna, fundamentada, no século XVI, nas interpretações de Moisés de Cordovero e de seu discípulo Isaac Luria, que Bloom pode propô-la como verdadeira "teoria da linguagem" e como método de abordagem crítica da literatura.

Enquanto, na Cabala clássica, a criação é vista como um "processo em progresso" (p. 48), desencadeado através das emanações divinas - as Sefirót -, e no qual cada estágio liga-se ao estágio imediatamente anterior, a Cabala moderna, em consolidação a partir de Luria, introduz uma noção radicalmente diversa: a criação - a realidade estruturada - surge pela recorrência de um processo trifásico, cujo evento central é sempre a catástrofe. Nessa interpretação, as fases da criação aparecem, respectivamente, como tzimtzum (contração); sheviráh (a quebra dos vasos - a catástrofe); e tikún (restituição, ou reconstrução) (p. 49). Não seria o caso de se detalhar, aqui, a complexa cosmogonia luriânica, mas deve-se ressaltar que, é nessa visão cabalística que surge a idéia de uma liberação do espaço exclusivamente divino - só possível pelo auto-ocultamento de Deus, a partir do tzimtzum para a Criação, para tudo o que não é Deus. A essa criação, Luria chama de "vasos" - sendo o homem o vaso culminante -; submetido à ocorrência perpétua de contração (limitação), quebra (catástrofe) e reaglutinação, o homem conservaria algo de Deus, sua luz primeira, sua Palavra.

Luria anteciparia, assim, uma teoria freudiana pela qual a paixão é necessária ao homem como forma de apaziguamento do eu. Também o Deus de Luria precisa criar para pacificar seu imensurável rigor , mas esse Deus só poderia criar por meio da catástrofe e, aqui, talvez Luria também estivesse antecipando a noção do corte lacaniano. Ao apresentar sucessivas interpretações das Escrituras, a Cabala propõe "dar um sentido ao sofrimento" (p. 61), mesmo que essas interpretações sejam objetivadas pelo uso de técnicas que mais evidenciam um aspecto místico - como a gematria esotérica -, que propriamente sua natureza mítica, destacada por Bloom. Para o teórico de Yale, no entanto, em sua derivação ocultista, a gematria cabalística deve ser considerada como um "índice do enorme sofrimento vivido pelos judeus" (p. 56), particularmente em sua luta no Exílio, que, para Luria, é a condição universal da existência humana (p. 52). Como modo de especulação intelectual e método interpretativo, a Cabala permite entrever um irresistível desejo de fuga a essa condição existencial ou, em última análise, o desejo de pôr fim ao sofrimento. Esse desejo encarna o próprio motivo da metáfora como possibilidade humana - talvez única possibilidade -, pela via da linguagem, de "ser diferente, de estar em qualquer outra parte", sendo, pois, também o motivo de toda a poesia. Nesse sentido, a poesia teria uma função antropopaica, assim como a religião, na visão de Bloom, que entende a Cabala como já sendo simplesmente poesia, prescindindo da necessidade de tradução para o domínio do estético.

Já no segundo capítulo de seu ensaio, Bloom irá explicitar uma "teoria da escrit", performada pela Cabala, em que não há uma distinção absoluta entre a escrita e a fala inspirada, assim como não há a distinção humana entre presença e ausência (p. 62). A negação de uma primazia da fala (enquanto presença e enquanto fenômeno precedente à escrita) é, na verdade, uma discussão da crítica contemporânea, mais especificamente desenvolvida pelo filósofo francês Jacques Derrida. Porém, essa "metafísica da presença" não estaria em causa nos domínios cabalísticos, já que, como afirma Bloom, "a Cabala interrompe o movimento do 'traço' de Derrida, pois ela tem um ponto do primordial, onde presença e ausência coexistem em interação contínua" (p. 63). É exatamente esse ponto que irá oferecer um modelo operativo para uma teoria da influência poética.

O caráter particularmente revisionista do Zohar, para Bloom, coloca a Cabala como uma forma de rebelião ao que poderia ser entendido como um "texto primeiro" - a Bíblia e a tradição judaica ortodoxa -, no que se refere aos episódios que relatam a Criação. É ainda a compreensão dessa posição revisionista da Cabala moderna que permitirá a Bloom tratar as Sefirót ativas, a saber: Héssed, Din, 
Tiféret, Netzáh, Hód e Yesód, ou as Behinót, na versão de Cordovero, como poemas da criação, apoiandose, para isso, nas complexas noções de primeiridade, secundidade e terceiridade, propostas pelo lingüista norte-americano Charles Sanders Peirce. Interessa, aqui, a definição literal de Peirce que será usada para sustentar a análise de Bloom: "Em sua forma genuína, a terceiridade é a relação triádica existente entre um signo, o seu objeto e o pensamento interpretante, ele mesmo um signo, considerado como constituindo o modo de ser de um signo. Um signo envolve uma mediação entre o signo interpretante e o seu objeto [...] Um Terceiro é qualquer coisa que faz um Primeiro se relacionar com um Segundo [...]" (p. 67). Bloom irá afirmar, a partir dessa noção, que um poema é uma idéia de Terceiridade, porque "o signo é o novo poema, seu objeto é o texto anterior (não importa se composto ou imaginário) e o pensamento interpretante é a leitura do poema, ela mesma um signo" (p. 73). Percorrendo um caminho tortuoso que vai, entre outros, do gnosticismo valentiano dos primeiros anos do cristianismo, ao neoplatonismo de Plotino e de Proclus (c. 410-485), para retornar a Cordovero e Luria, Bloom busca uma genealogia da angústia e do ressentimento que marcam as relações entre textos terceiros, no sentido peirciano (os comentários, as interpretações, a Cabala) e seus precursores (os textos platônicos, a Bíblia).

Advém, da leitura erudita de Bloom, a possibilidade de se compreender a relação entre a poesia - de fato, toda a literatura -, mobilizando-se um conceito que implica um movimento em direção ao "conhecimento", e sua história. Em outras palavras, esse percurso permite a Bloom concluir que, "quando se conhece tanto o precursor quanto o poeta posterior, se conhece a história poética, mas este conhecimento representa um evento tão crucial nesta história quanto era o conhecimento que tinha o efebo de seu antecessor" (p. 67). É nesse ponto que se encontra a principal contribuição desse estudo de Bloom para a teoria literária, impondo a essa teoria também uma revisão quanto às categorias do ser para que se possa lidar, então, com um conceito de acontecer, mais produtivo, reconhecendo o próprio conhecimento que se tem acerca da influência de um texto precursor sobre seu sucedâneo como uma forma de entrada dinâmica, percebendo que o poeta - o artista - só cria pela "desleitura" de seu antecessor, operando uma espécie de desconstrução - então, um evento central, uma catástrofe, na história da literatura, da arte, da cultura.

Compreender essa dinâmica é assumir, como propõe Bloom, no terceiro e último capítulo de Cabala e crítica, que "todo ato de leitura é um ato de tardividade" (p. 106), e, como tal, implica uma necessária desleitura, uma interpretação defensiva que, em última análise, é o que garante a vitalidade de qualquer cultura, vale dizer, pela continuidade da tradição. E, como está em Bloom, isso significa muito mais: "todo leitor é um efebo, todo poema, um precursor, e toda leitura, um ato de 'influência', ou seja, o ato de ser influenciado pelo poema e de influenciar qualquer outro leitor para quem seja comunicada a sua leitura" (p. 67). É exatamente essa afirmação de Bloom que nos permite ir além de certo determinismo que, não sendo de todo inevitável, não se deixa aprisionar numa relação meramente dialética. A leitura poética propriamente dita, enfoque desse capítulo, não se apresenta, a partir das reflexões de Bloom, como um ato passivo de reverência ao texto primeiro, mas deve reconhecer nele, já uma desleitura e também uma reconstrução anteriores. (Des)apropriada a metáfora trifásica de Luria, em certo sentido, toda reconstrução será uma "nova construção", tão inédita quanto pode ser qualquer criação, se desprovida da angústia de conter em si as "luzes" de sua matéria original, para sempre perdida na história.

* Vívien Gonzaga e Silva é Mestre em Letras pela UFMG, professora de Língua Portuguesa e Literatura Brasileira no Colégio Técnico da UFMG e pesquisadora do Núcleo de Estudos Judaicos da UFMG. 